\title{
Malpighian tubules are important determinants of Pseudomonas transstadial transmission and longtime persistence in Anopheles stephensi
}

\author{
Ali Reza Chavshin ${ }^{1,2}$, Mohammad Ali Oshaghi $^{3^{*}}$, Hasan Vatandoost ${ }^{3,4}$, Bagher Yakhchali ${ }^{5}$, Fahimeh Zarenejad ${ }^{5}$ \\ and Olle Terenius ${ }^{6^{*}}$
}

\begin{abstract}
Background: Pseudomonas is a genus of bacteria commonly found in investigations of gut microbes in malaria mosquitoes. Among those mosquitoes is the dominating malaria vector in Asia, Anopheles stephensi, where Pseudomonas is a prevailing bacterium and natural inhabitant of its breeding places. In order to explore the reason for finding Pseudomonas so frequently, an investigation of its localization and transstadial properties was undertaken.

Methods: A Pseudomonas isolate from An. stephensi was transformed successfully with an endogenous plasmid modified to express green fluorescent protein (GFP). Subsequently, the Pseudomonas-GFP was added to the laboratory larval breeding place of An. stephensi and taken up by the larvae. After 24 hours, the larvae were cleaned and moved to a bath with double-distilled water. Also, female adults were fed sugar solution containing Pseudomonas-GFP. The Pseudomonas-GFP was traced in the alimentary canal of larvae, pupae and adults.

Results: Fluorescent microscopy and PCR assays showed that the Pseudomonas bacteria underwent transstadial transmission from larvae to pupae and then to adults. In blood-fed female mosquitoes, the bacteria increased in numbers and remained in the mosquito body for at least three weeks after eclosion. In addition to the midgut, the Malpighian tubules of both larvae and adult mosquitoes were colonized by the bacteria. Also Pseudomonas-GFP that was distributed through sugar solution was able to colonize the Malpighian tubules of adult females.

Conclusions: Colonization of the Malpighian tubules by Pseudomonas bacteria seems to be important for the transstadial passage from larvae to adult and presumably for the longevity of the bacteria in the adult mosquito. The existence of an entry point in the larval stage, and the long duration in the female gut, opens up for a possible use of Pseudomonas in mosquito paratransgenesis.
\end{abstract}

Keywords: Malaria, Anopheles stephensi, Pseudomonas, GFP, Transstadial transmission, Paratransgenesis

\section{Background}

Insect gut bacteria live in an environment where the host organism and other microorganisms influence the conditions. One can expect an element of coadaptation between the bacteria and their host at least for bacteria that are beneficial for the host for food degradation or for suppression of harmful bacteria. Some bacteria are living in such close relationship with their insect hosts

\footnotetext{
*Correspondence: moshaghi@sina.tums.ac.ir; Olle.Terenius@slu.se ${ }^{3}$ Department of Medical Entomology and Vector Control, School of Public Health, Tehran University of Medical Sciences (TUMS), Tehran, Iran ${ }^{6}$ Department of Ecology, Swedish University of Agricultural Sciences (SLU), Uppsala, Sweden

Full list of author information is available at the end of the article
}

that they now lack certain functions that would enable them to live outside their host. Well-studied examples include the microbiota in termites [1] and the genus Buchnera in aphids [2]. Also some important vectors of disease have obligate midgut bacterial symbionts. For example, the vector for Chagas disease, the kissing bug Rhodnius prolixus that carry blood-degrading Rhodococcus rhodnii [3] and tsetse flies that carry the symbiont Wigglesworthia glossinidia [4]. In mosquitoes, two of the key questions regarding gut bacteria have concerned persistence of bacteria and whether bacteria can be transferred over developmental stages, so called transstadial transmission. For certain bacteria, such as Wolbachia, 
recently found in Anopheles gambiae and Anopheles coluzzi [5], the intracellular life of the bacteria secure a transstadial transmission. Likewise, the genus Asaia has been shown to infect reproductive tissues and also undergo transstadial transmission [6,7].

Mosquito-borne diseases are serious health problems around the world and more than half of the world population is at risk of getting infected. For several mosquitoborne diseases, especially in the case of malaria, control mainly depends on the use of insecticides and related methods such as insecticide-treated nets (ITNs). However, while great achievements have been made using routine malaria control programs, the current tools are at stake because of problems arising such as insecticide resistance in Anopheles mosquitoes, drug resistance in the malaria parasites and lack of an effective vaccine. Consequently, this has forced researchers to develop other methods including transgenesis and paratransgenesis. For vector transgenesis, the goal is to genetically modify vectors [8], while for paratransgenesis, the goal is to modify symbiotic bacteria of the vector to deliver anti-parasitic effector molecules to wild vector populations. Paratransgenesis can also be used to express substances with pathogenic effects that interfere with the mosquito reproduction and shorten the life span $[6,8,9]$. The basic and most important step in paratransgenesis is to find suitable bacteria. They should dominate the insect microflora, infest a part of vector body where they are in close contact with the pathogen, and be adapted to the immunological and physiological condition of the vector body. Also, transstadial transmission is an important criterion since it would enable the genetically engineered bacteria to be introduced into the larval breeding places and then be naturally transferred to the adults.

Pseudomonas bacteria have in previous studies often been a common member of the gut flora in malaria mosquitoes (Table 1). From the studies performed, it seems that Pseudomonas is more abundant in Anopheles mosquitoes from the Indian subcontinent and the Arabian Peninsula than in Africa, and also more abundant in $A n$. stephensi than in other species. Whether this is a general fact and whether this is dependent on mosquito species or environmental differences remains to be seen. Recently, it was shown that in Anopheles culicifacies and An. stephensi identical sequences of $16 \mathrm{~S}$ for Pseudomonas bacteria were found in both larvae and adults indicating that a transstadial transmission was possible $[10,11]$. In this study, transstadial transmission, colonization site, and the effect of blood- and sugar-feeding was investigated for a Pseudomonas isolate from Anopheles stephensi, the main malaria vector in Asia.

\section{Methods}

\section{Bacterial transformation}

A Pseudomonas species was previously isolated from $A n$. stephensi larvae [11] and selected for this study because of its dominant presence both in larvae and adults. The isolate (BND-YL1; GenBank accession no. HQ832847) is most closely related to Pseudomonas extremaustralis. A $\sim 4 \mathrm{~kb}$ endogenous plasmid was successfully extracted from the BND-YL1 isolate using a high pure plasmid isolation kit (Roche) according to the manufacturer's instructions. After evaluating several enzymes, the extracted plasmid was digested with BamHI and HindIII and a GFP gene was inserted using T4 DNA ligase. Competent cells of the BND-YL1 isolate were transformed by electroporation [18] with its native plasmid expressing GFP. The transformed bacteria were examined by fluorescent microscopy and PCR amplification with GFP-specific primers. Colonies with successful GFP expression (hereafter called Pseudomonas-GFP) were selected and used for further studies.

\section{Establishment of Pseudomonas-GFP in mosquitoes}

For experiments we used a laboratory-reared strain of An. stephensi (originally from south of Iran and kept at

Table 1 Presence of Pseudomonas in studies on Anopheles gut flora

\begin{tabular}{llll}
\hline Mosquito species & Frequency & Reference & Region \\
\hline An. albimanus & $17 \%$ & {$[12]$} & Laboratory reared, USA, North America \\
An. culicifacies & Most common, 57\% & {$[10]$} & Iran, Asia \\
An. darlingi & $5 \%$ (3 of 57) & {$[13]$} & Brazil, South America \\
An. gambiae & $17 \%$ & {$[12]$} & Laboratory reared, USA, North America \\
An. gambiae & $1.65 \%$ & {$[14]$} & Cameroon, Africa \\
An. gambiae & $0.05-5.37 \%$ depending on stage & {$[15]$} & Partly laboratory reared, Kenya, Africa \\
An. maculipennis & Pseudomonas sp. were detected in most of the specimens analyzed & {$[16]$} & Iran, Asia \\
An. stephensi & $38 \%$ & {$[12]$} & Laboratory reared, USA, North America \\
An. stephensi & Pseudomonas sp. were detected in most of the specimens analyzed & {$[16]$} & Iran, Asia \\
An. stephensi & Pseudomonas was the most frequent (51\% in larvae and 54\% in adults) & {$[11]$} & Iran, Asia \\
An. stephensi & Pseudomonas mendocina and Serratia marcescens were the most abundant & {$[17]$} & Laboratory reared, India, Asia \\
\hline
\end{tabular}


Table 2 Dissection scheme with number of adult mosquitoes dissected per time point ${ }^{\mathrm{a}}$

\begin{tabular}{llll}
\hline Hours post blood meal & \multicolumn{3}{l}{ Days after emergence } \\
\cline { 2 - 4 } & $\mathbf{2}$ & $\mathbf{3}$ & $\mathbf{1 0}$ \\
\hline $0^{\mathrm{b}}$ & 3 & 3 & 3 \\
24 & & 3 & 3 \\
48 & 3 & 3 \\
72 & & 3 & 3 \\
\hline
\end{tabular}

${ }^{a}$ This scheme applies for each of the groups of mosquitoes fed with Pseudomonas-GFP as larvae, adults fed with sugar containing Pseudomonas-GFP, and the controls of respective experiment.

${ }^{\mathrm{b}}$ Before blood feeding.

Department of Medical Entomology, School of Public Health, Tehran University of Medical Sciences, SPHTUMS). The mosquitoes were reared at $25 \pm 2^{\circ} \mathrm{C}$ with $70 \%$ humidity.

Fifty first instar larvae were reared in trays including $10^{6}$ CFU Pseudomonas-GFP plus ampicillin $100 \mu \mathrm{g} / \mathrm{ml}$. After 24 hours, the larvae were removed and washed twice in separate baths of $\mathrm{ddH}_{2} \mathrm{O}$ to eliminate the bacteria on the larval body surface and then transferred to $\mathrm{ddH}_{2} \mathrm{O}$ plus ampicillin $(100 \mu \mathrm{g} / \mathrm{ml})$. The larvae were reared for the rest of their lives in the ampicillinadded $\mathrm{dd}_{2} \mathrm{O}$. The larvae were left to pupate, and emerged at adult stage from the same water they pupated in. At least two individuals were dissected from each stage (L2, L3, L4 and pupae). The presence of GFP-producing bacteria in their organs was examined by microscopy.

\section{Adult experiments using Pseudomonas-GFP}

Two parallel experiments were performed for adults. In the first experiment, the larvae which acquired Pseudomonas-GFP bacteria were allowed to pupate and eclose. The emerged female adults were dissected two, three, and ten days after eclosion (Table 2). The females were artificially blood fed with defibrinated cow blood on day three and on day ten in order to study the effect of blood meals on colonization of Pseudomonas-GFP in mosquito midguts and other organs. The blood fed mosquitoes were dissected and examined by fluorescent microscopy 24,48 or $72 \mathrm{~h}$ post blood feeding (Table 2).

In the second experiment, female adults raised without Pseudomonas-GFP were fed with sugar containing Pseudomonas-GFP bacteria. These adults were then blood fed and examined as above.

\section{Detection of GFP-expressing Pseudomonas}

The mosquitoes were examined by fluorescent microscopy using a BX61 microscope, with U-LH100HGAPO lamp houses and DP-70 imaging system (Olympus). In all fluorescent microscopy surveys, larvae or adult mosquitoes with no exposure to the GFP-expressing bacteria were examined as negative controls to ensure that the green light observed originated from the GFP-expressing bacteria and not was due to auto-fluorescence.

To reconfirm the presence of Pseudomonas-GFP bacteria in the mosquitoes we performed PCR with GFPspecific primers. Briefly, before dissection the mosquito surface was sterilized with $70 \%$ ethanol [19]. Then the
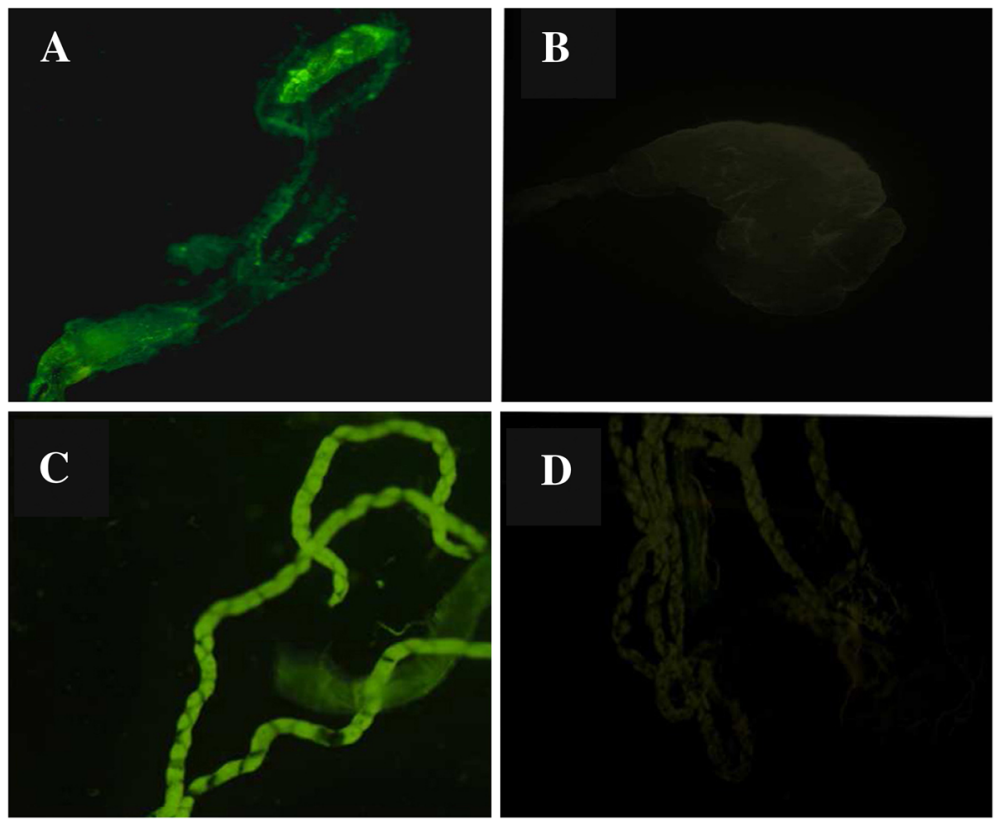

Figure 1 Colonization of Pseudomonas-GFP in larval midgut and Malpighian tubules. (A) midgut, (B) midgut negative control (C) Malpighian tubules, (D) Malpighian tubules negative control. 

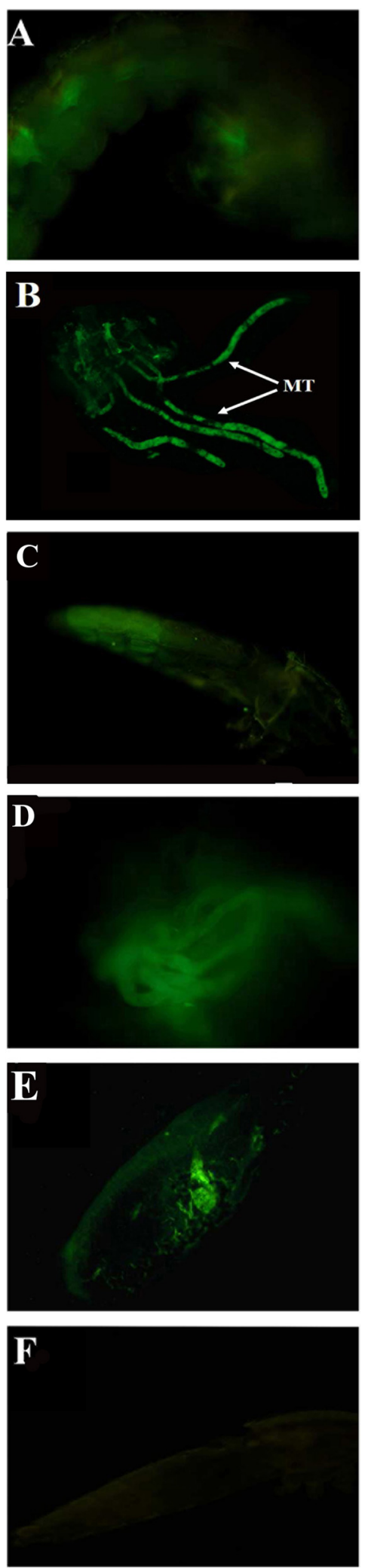

Figure 2 Colonization and transstadial transmission of Pseudomonas-GFP bacteria in An. stephensi. (A) live pupa, (B) Malpighian tubules of dissected pupa, (C) live adult, (D) Malpighian tubules of live adult, (E) dissected adult midgut, (F) live adult negative control.

specimen was dissected under sterile conditions, and the midgut was mashed and suspended in $500 \mu \mathrm{L}$ of Brain Heart Infusion (BHI) and incubated for 24-48 hours at $37^{\circ} \mathrm{C}$. DNA of the grown bacteria was extracted using QIAGEN DNeasy Kit (Qiagen, Germany) according to the manufacturer's instructions. The GFP-gene primers, GFPF 5'-CAAGAGTGCCATGCCCGAAGG-3' and GFP-R 5'-GACAGGGCCATCGCCAATTGG-3', were used to obtain a 280 bp band $[20,21]$. The PCR conditions were $94^{\circ} \mathrm{C}$ for 10 minutes, followed by 35 cycles of $\left[95^{\circ} \mathrm{C}\right.$ for 30 seconds, $62^{\circ} \mathrm{C}$ for 40 seconds, $72^{\circ} \mathrm{C}$ for 30 seconds], and $72^{\circ} \mathrm{C}$ for 8 minutes.

\section{Results and discussion}

In a number of studies, larval midgut bacteria has been said to be transmitted transstadially to the adult gut [12,22-24]. In most of these studies, the same bacteria have been found both in larvae and in adults, which could be interpreted as transstadial transmission. These findings contradict the common notion that the midgut bacteria of mosquito larvae are removed during metamorphosis and formation of the peritrophic membrane in larvae [25]. An alternative explanation to finding the same bacteria in the adults as in the larvae, could be that immediately after emergence adult mosquitoes take a sip of water from their hatching environment [26]. However, in An. stephensi we have shown that for Escherichia coli the bacterial persistence could also be due to escape from the metamorphosis using the Malpighian tubules as a covert [27]. It is known that the larval Malpighian tubules remain intact during metamorphosis in Drosophila $[28,29]$ and tubular fluid including the bacteria may drain from Malpighian tubules towards the midgut at the junction point of midgut/hindgut and Malpighian tubules. To further explore the possibility of a Malpighiantubules hide-out as an explanation for the common presence of Pseudomonas in malaria mosquitoes, we investigated whether Pseudomonas belonging to the natural flora of $A n$. stephensi [11], also are able to colonize the Malpighian tubules in a similar manner.

We initiated the investigation by successfully transforming an endogenous plasmid into the Pseudomonas isolate BND-YL1, as determined by GFP expression and PCR amplification of the GFP gene sequence (data not shown). Then the genetically transformed Pseudomonas was added to the breeding water of $1^{\text {st }}$ instar An. stephensi larvae. After 24 hours, the larvae were cleaned and moved to a bath with $\mathrm{ddH}_{2} \mathrm{O}$. At the $4^{\text {th }}$ instar stage, 

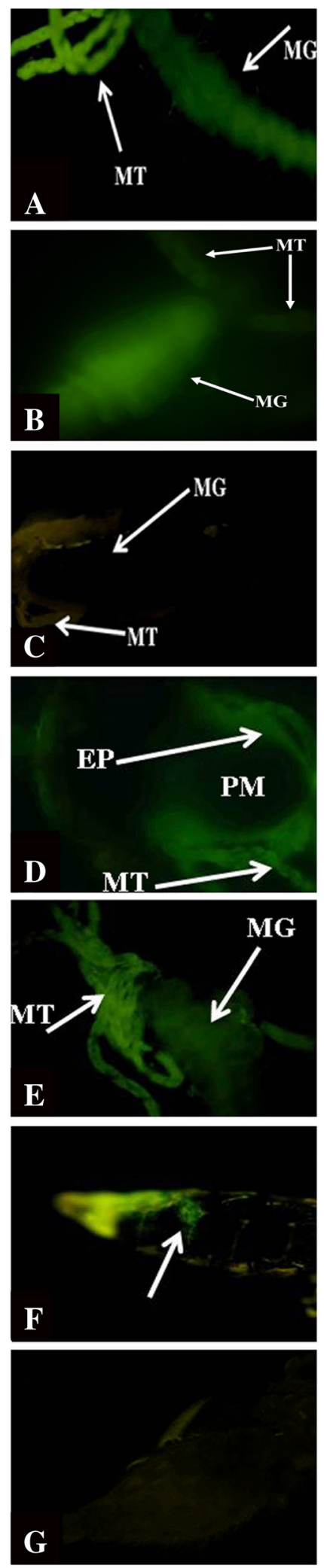

Figure 3 Colonization of Pseudomonas-GFP in adult females.

(A-C) Dissected mosquitoes after feeding sugar containing

Pseudomonas-GFP; (A) One week old, no blood feeding; (B) 3 weeks old, blood-fed at days 3 and 10; (C) negative control; (D-G) Mosquitoes receiving Pseudomonas-GFP as larvae, 48 hours after third gonotrophic cycle; (D-E) Dissected mosquitoes; (F) Abdomen of live mosquito;

(G) Negative control. (EP) epithelial cell line. (MG) midgut. (MT) Malpighian tubules. (PM) peritrophic matrix.

all larvae showed expression of GFP in the larval midgut (Figure 1A), but the colonization was particularly intense in the Malpighian tubules (Figure 1C). GFP expression was also seen in all pupae and adults (Figure 2). The transstadial transmission of the Pseudomonas isolate BND-YL1 was confirmed both by fluorescent microscopy and PCR amplification of the GFP gene.

The successful transstadial transmission opened up for exploring the potential use of Pseudomonas for mosquito paratransgenesis; a pathogen-interference approach in which a genetically modified bacterium produces substances incapacitating the pathogens in adult mosquitoes [30]. Introducing a genetically modified symbiont into wild populations is regarded as more feasible in the larval stage where mosquito larvae are concentrated in breeding sites and also largely feed on bacteria. Therefore our discovery of bacteria having the ability of transstadial transmission could be an important step in a paratransgenesis approach for malaria control. An alternative approach is to supply adult females with modified bacteria in sugar containers [30]. Therefore, we also investigated whether the bacteria could reach the Malpighian tubules by feeding sugar solution containing Pseudomonas-GFP. Indeed, also all 27 female adults revealed successful bacterial establishment in the mosquito Malpighian tubules (Figure 3).

However, to interact with malaria parasites, the bacteria must also proliferate in the gut upon a blood meal and preferably remain in the gut a prolonged time to be established at renewed blood meals. To explore the effect of blood feeding on the Pseudomonas bacteria, female An. stephensi were offered blood. The number of Pseudomonas bacteria increased substantially after a blood meal, which is in agreement with previous studies [27,31-33] that also showed an increased number of gut bacteria post-blood feeding. In An. gambiae it was shown that Pseudomonas bacteria had a statistically significant increase after a blood meal and that it could be linked to its ability to withstand oxidative stress [15]. The fluorescent intensity was highest about 24-48 hours after blood feeding (Figure 3D-F) and in our experiments, where the mosquitoes were blood fed once a week, fluorescent bacteria could be observed in the mosquito midgut more than 3 weeks (Figure 3B). Each gonotrophic cycle takes about two-three days under our lab conditions; therefore, the bacteria remained alive without 
additional blood meal nutrients for at least four to five days more. The 3 week-survival of Pseudomonas in the mosquito body is enough to cover a period of several potential Plasmodium infections in the vector body and is a substantial increase in time as compared to our previous data with GFP-expressing $E$. coli that remained 13 days in mosquitoes of the same colony [27].

The colonization of Malpighian tubules could also make Pseudomonas species potential candidates for paratransgenesis against pathogens for which a part of the life cycle is related to Malpighian tubules. For instance, the method could be used against Dirofilaria immitis, one of the causing agents of zoonotic dirofilariasis, which is endemic in several parts of southern Europe [34], United States of America [35], some parts of Asia [36], and the Middle East [37]. One has to consider though that among the more than 100 Pseudomonas species some are pathogenic. One example is Pseudomonas aeruginosa, which is an opportunistic human pathogen in severely immunocompromised patients [38]. Therefore, only Pseudomonas species that are nonpathogenic should be selected for a paratransgenesis approach.

\section{Conclusions}

In this study, we showed that Pseudomonas bacteria can survive and stay successfully in the midgut of mosquitoes during several molting or ecdysis events during larval stages as well as hydrolytic processes during metamorphosis and finally transfer to adults. Also, the bacteria were localized in midgut as well as Malpighian tubules, increased following blood meals, and remained in the lumen of adult mosquitoes more than 21 days after eclosion. Although our data could suggest that a non-pathogenic Pseudomonas bacteria would be useful in a paratransgenesis approach, further studies would be needed to engineer the Pseudomonas isolate with some effector molecules and to test the ability of the recombinant bacterium to block parasite transmission in the laboratory and under field conditions.

\section{Competing interests}

The authors declare that they have no competing interests.

\section{Authors' contributions}

ARC, MAO and HV designed the project. ARC did the experiments, recorded the results and analyzed them. BY and FZ assisted the process of plasmid digestion and Pseudomonas transformation. MAO, HV and OT supervised the project. ARC, MAO and OT wrote the draft of manuscript. OT finalized the manuscript. All authors read the final version of the manuscript and approved its content.

\section{Acknowledgments}

This work was financially supported by Tehran University of Medical Sciences (TUMS) and Swedish University of Agricultural Sciences (SLU). The authors would like to thank MR Abai, F Rafi and AH Hosseini, for their kind assistance with mosquito rearing.

\section{Author details}

${ }^{1}$ Social Determinants of Health, Research Center, Urmia University of Medical Sciences (UMSU), Urmia, Iran. ${ }^{2}$ Department of Medical Entomology and Vector Control, School of Public Health, Urmia University of Medical Sciences (UMSU), Urmia, Iran. ${ }^{3}$ Department of Medical Entomology and Vector Control, School of Public Health, Tehran University of Medical Sciences (TUMS), Tehran, Iran. ${ }^{4}$ Institute for Environmental Research (IER), Tehran, Iran. ${ }^{5}$ Department of Environmental Biotechnology, National Institute of Genetic Engineering and Biotechnology (NIGEB), Tehran, Iran. ${ }^{6}$ Department of Ecology, Swedish University of Agricultural Sciences (SLU), Uppsala, Sweden.

Received: 22 September 2014 Accepted: 2 January 2015

Published online: 21 January 2015

\section{References}

1. Abe T, Bignell D, Higashi M. Termites: Evolution, Sociality, Symbiosis, Ecology. Dordrecht: Kluwer; 2000.

2. Douglas AE. Nutritional interactions in insect-microbial symbioses: Aphids and their symbiotic bacteria Buchnera. Annu Rev Entomol. 1998;43:17-37.

3. Beard CB, Mason PW, Aksoy S, Tesh RB, Richards FF. Transformation of an insect symbiont and expression of a foreign gene in the Chagas' disease vector Rhodnius prolixus. Am J Trop Med Hyg. 1992;46(2):195-200.

4. Aksoy S. Wigglesworthia gen. nov. and Wigglesworthia glossinidia sp. nov., taxa consisting of the mycetocyte-associated, primary endosymbionts of tsetse flies. Int J Syst Bacteriol. 1995;45(4):848-51.

5. Baldini F, Segata N, Pompon J, Marcenac P, Robert Shaw W, Dabire RK, et al. Evidence of natural Wolbachia infections in field populations of Anopheles gambiae. Nat Comm. 2014;5:3985.

6. Favia G, Ricci I, Damiani C, Raddadi N, Crotti E, Marzorati M, et al. Bacteria of the genus Asaia stably associate with Anopheles stephensi, an Asian malarial mosquito vector. Proc Natl Acad Sci U S A. 2007;104(21):9047-51.

7. Damiani C, Ricci I, Crotti E, Rossi P, Rizzi A, Scuppa P, et al. Paternal transmission of symbiotic bacteria in malaria vectors. Curr Biol. 2008;18(23):R1087-8.

8. Coutinho-Abreu IV, Zhu KY, Ramalho-Ortigao M. Transgenesis and paratransgenesis to control insect-borne diseases: current status and future challenges. Parasitol Int. 2010;59(1):1-8.

9. Aksoy S, Weiss B, Attardo G. Paratransgenesis applied for control of tsetse transmitted sleeping sickness. Adv Exp Med Biol. 2008;627:35-48.

10. Chavshin AR, Oshaghi MA, Vatandoost H, Pourmand MR, Raeisi A, Terenius O. Isolation and identification of culturable bacteria from wild Anopheles culicifacies, a first step in a paratransgenesis approach. Parasit Vectors. 2014;7:419.

11. Chavshin AR, Oshaghi MA, Vatandoost H, Pourmand MR, Raeisi A, Enayati $A A$, et al. Identification of bacterial microflora in the midgut of the larvae and adult of wild caught Anopheles stephensi: a step toward finding suitable paratransgenesis candidates. Acta Trop. 2012;121(2):129-34.

12. Pumpuni CB, Demaio J, Kent M, Davis JR, Beier JC. Bacterial population dynamics in three anopheline species: the impact on Plasmodium sporogonic development. Am J Trop Med Hyg. 1996;54(2):214-8.

13. Terenius $O$, de Oliveira CD, Pinheiro WD, Tadei WP, James AA, Marinotti $O$. $16 \mathrm{~S}$ rRNA gene sequences from bacteria associated with adult Anopheles darlingi (Diptera: Culicidae) mosquitoes. J Med Entomol. 2008;45(1):172-5.

14. Boissiere A, Tchioffo MT, Bachar D, Abate L, Marie A, Nsango SE, et al. Midgut microbiota of the malaria mosquito vector Anopheles gambiae and interactions with Plasmodium falciparum infection. PLoS pathogens. 2012;8(5):e1002742.

15. Wang Y, Gilbreath 3rd TM, Kukutla P, Yan G, Xu J. Dynamic gut microbiome across life history of the malaria mosquito Anopheles gambiae in Kenya. PLOS ONE. 2011;6(9):e24767.

16. Djadid ND, Jazayeri H, Raz A, Favia G, Ricci I, Zakeri S. Identification of the midgut microbiota of An. stephensi and An. maculipennis for their application as a paratransgenic tool against malaria. PLoS ONE. 2011;6(12):e28484.

17. Rani A, Sharma A, Rajagopal R, Adak T, Bhatnagar RK. Bacterial diversity analysis of larvae and adult midgut microflora using culture-dependent and culture-independent methods in lab-reared and field-collected Anopheles stephensi-an Asian malarial vector. BMC Microbiol. 2009;9:96.

18. Sambrook J, Russell DW. Molecular cloning: a laboratory manual, vol. 1-3. Cold Spring Harbor, New York: Cold Spring Harbor Laboratory Press; 2001. 
19. Pidiyar VJ, Jangid K, Patole MS, Shouche YS. Studies on cultured and uncultured microbiota of wild Culex quinquefasciatus mosquito midgut based on $16 \mathrm{~s}$ ribosomal RNA gene analysis. Am J Trop Med Hyg. 2004;70(6):597-603.

20. Li J, McLellan S, Ogawa S. Accumulation and fate of green fluorescent labeled Escherichia coli in laboratory-scale drinking water biofilters. Water Res. 2006;40(16):3023-8.

21. Sarrazin S, Mossadegh-Keller N, Fukao T, Aziz A, Mourcin F, Vanhille L, et al. MafB Restricts M-CSF-Dependent Myeloid Commitment Divisions of Hematopoietic Stem Cells. Cell. 2009;138(2):300-13.

22. Briones AM, Shililu J, Githure J, Novak R, Raskin L. Thorsellia anophelis is the dominant bacterium in a Kenyan population of adult Anopheles gambiae mosquitoes. ISME J. 2008;2(1):74-82.

23. Jadin J, Vincke IH, Dunjic A, Delville JP, Wery M, Bafort J, et al. Role of Pseudomonas in the sporogenesis of the hematozoon of malaria in the mosquito. Bull Soc Pathol Exot Filiales. 1966;59(4):514-25.

24. Coon KL, Vogel KJ, Brown MR, Strand MR. Mosquitoes rely on their gut microbiota for development. Mol Ecol. 2014;23(11):2727-39.

25. Moll RM, Romoser WS, Modrzakowski MC, Moncayo AC, Lerdthusnee K. Meconial peritrophic membranes and the fate of midgut bacteria during mosquito (Diptera: Culicidae) metamorphosis. J Med Entomol. 2001;38(1):29-32.

26. Lindh JM, Borg-Karlson AK, Faye I. Transstadial and horizontal transfer of bacteria within a colony of Anopheles gambiae (Diptera: Culicidae) and oviposition response to bacteria-containing water. Acta Trop. 2008;107(3):242-50.

27. Chavshin AR, Oshaghi MA, Vatandoost H, Yakhchali B, Raeisi A, Zarenejad F. Escherichia coli expressing a green fluorescent protein (GFP) in Anopheles stephensi: a preliminary model for paratransgenesis. Symbiosis. 2013;60:17-24.

28. Singh SR, Hou SX. Multipotent stem cells in the Malpighian tubules of adult Drosophila melanogaster. J Exp Biol. 2009;212(Pt 3):413-23.

29. Gautam NK, Tapadia MG. Ecdysone signaling is required for proper organization and fluid secretion of stellate cells in the Malpighian tubules of Drosophila melanogaster. Int J Dev Biol. 2010;54(4):635-42.

30. Riehle MA, Jacobs-Lorena M. Using bacteria to express and display antiparasite molecules in mosquitoes: current and future strategies. Insect Biochem Mol Biol. 2005;35(7):699-707.

31. Gaio Ade O, Gusmão DS, Santos AV, Berbert-Molina MA, Pimenta PF, Lemos FJ. Contribution of midgut bacteria to blood digestion and egg production in Aedes aegypti (Diptera: Culicidae) (L.). Parasit Vectors. 2011;4:105.

32. Pumpuni CB, Beier MS, Nataro JP, Guers LD, Davis JR. Plasmodium falciparum: inhibition of sporogonic development in Anopheles stephensi by gram-negative bacteria. Exp Parasitol. 1993;77(2):195-9.

33. Riehle MA, Moreira CK, Lampe D, Lauzon C, Jacobs-Lorena M. Using bacteria to express and display anti-Plasmodium molecules in the mosquito midgut. Int J Parasitol. 2007;37(6):595-603

34. Muro A, Genchi C, Cordero M, Simón F. Human Dirofilariasis in the European Union. Parasitology Today. 1999;15(9):386-9.

35. Theis JH. Public health aspects of dirofilariasis in the United States. Vet Parasitol. 2005;133:157-80.

36. Kan SP, Rajah KV, Dissanaike AS. Survey of dirofilariasis among dogs in seremban, Malaysia. Vet Parasitol. 1977;3(2):177-81.

37. Azari-Hamidian S, Yaghoobi-Ershadi MR, Javadian E, Abai MR, Mobedi I, Linton YM, et al. Distribution and ecology of mosquitoes in a focus of dirofilariasis in northwestern Iran, with the first finding of filarial larvae in naturally infected local mosquitoes. Med Vet Entomol. 2009:23(2):111-21.

38. Gellatly SL, Hancock REW. Pseudomonas aeruginosa: new insights into pathogenesis and host defenses. Pathog Dis. 2013:67(3):159-73.

\section{Submit your next manuscript to BioMed Central and take full advantage of:}

- Convenient online submission

- Thorough peer review

- No space constraints or color figure charges

- Immediate publication on acceptance

- Inclusion in PubMed, CAS, Scopus and Google Scholar

- Research which is freely available for redistribution

Submit your manuscript at www.biomedcentral.com/submit 